
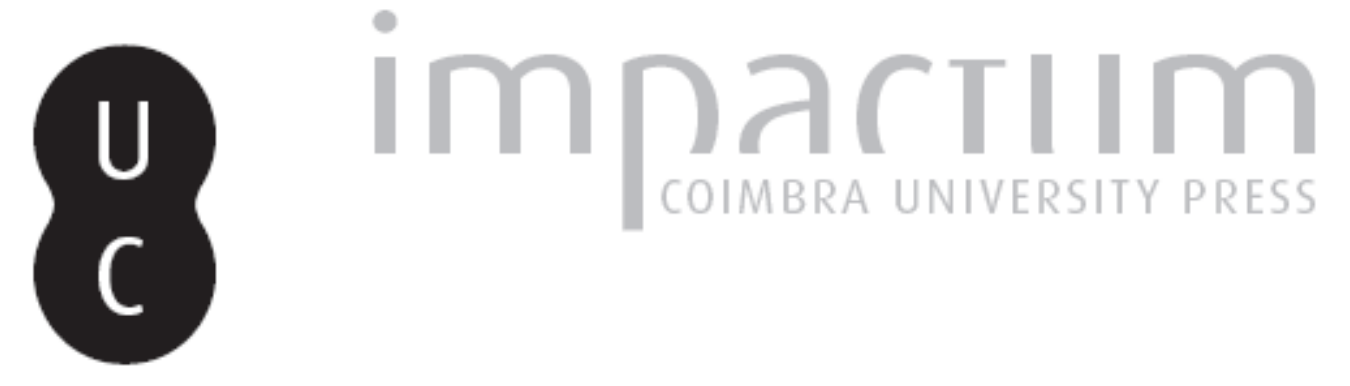

\title{
Texto e tradução: a inquietação do tradutor
}

\section{Autor(es): $\quad$ Periquito, Margarida}

Publicado por: Imprensa da Universidade de Coimbra

URL persistente:

URI:http://hdl.handle.net/10316.2/42604

DOI:

DOl:https://doi.org/10.14195/0870-8584_3_1

Accessed : $\quad$ 26-Apr-2023 16:31:10

A navegação consulta e descarregamento dos títulos inseridos nas Bibliotecas Digitais UC Digitalis, UC Pombalina e UC Impactum, pressupõem a aceitação plena e sem reservas dos Termos e Condições de Uso destas Bibliotecas Digitais, disponíveis em https://digitalis.uc.pt/pt-pt/termos.

Conforme exposto nos referidos Termos e Condições de Uso, o descarregamento de títulos de acesso restrito requer uma licença válida de autorização devendo o utilizador aceder ao(s) documento(s) a partir de um endereço de IP da instituição detentora da supramencionada licença.

Ao utilizador é apenas permitido o descarregamento para uso pessoal, pelo que o emprego do(s) título(s) descarregado(s) para outro fim, designadamente comercial, carece de autorização do respetivo autor ou editor da obra.

Na medida em que todas as obras da UC Digitalis se encontram protegidas pelo Código do Direito de Autor e Direitos Conexos e demais legislação aplicável, toda a cópia, parcial ou total, deste documento, nos casos em que é legalmente admitida, deverá conter ou fazer-se acompanhar por este aviso.

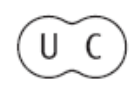




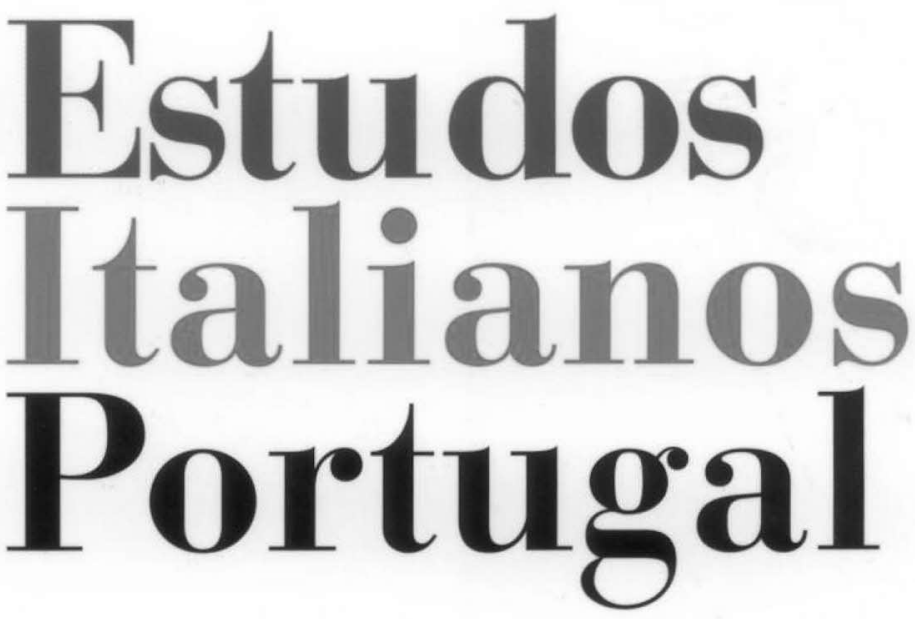

Instituto

Italiano

de Cultura

de Lisboa

Nova Série

$\mathrm{N}^{\circ} 3$

2008 
TEXTO E TRADUÇÃO:

A INQUIETAÇÃO DO TRADUTOR

Margarida Periquito*

O poema de Ludovico Ariosto, Orlando Furioso, tem como ponto central e fulcral um acontecimento que é anunciado, logo no exórdio do poema (I:2:1-3), como grande novidade: a loucura, por amor, de Orlando. No Orlando Furioso, estar/ficar "louco de amor" significa mesmo enlouquecer. Orlando enlouquece literalmente.

Esse acontecimento dá-se no Canto XXIII, ápice geométrico do poema e da sua estrutura, visto que se compõe de 46 cantos.

Até àquele ponto existe uma conjunção de factos em crescendo que vêm a culminar na loucura, e a partir dali há uma sinergia no sentido de o paladino vir a readquirir o siso perdido.

O Canto XXIII funciona, pois, como um ponto de cisão, uma charneira que divide dois mundos: o velho mundo cavaleiresco, atido às suas regras rígidas, e o novo mundo em que essas regras se diluem, propiciando atitudes mais próximas do humanismo renascentista.

Sintomática dessa mudança é a reaparição, no canto final, de Rodomonte, herói sarraceno que se auto-impusera o castigo de permanecer mais de um ano encerrado numa gruta, por ter sido derrotado em combate. Tendo estado ausente da evolução dos acontecimentos, Rodomonte ressurge como

* Tradutora de Orlando Furioso. Texto lido na apresentação da obra, no Instituto Italiano de Cultura, Lisboa, em 21 de Fevereiro de 2008. 
a figura do velho mundo que se confronta com os valores do novo mundo. Morre às mãos de Ruggiero, já não a golpes de lança ou espada, mas de punhal.

No fatídico Canto XXIII, Orlando vagueia dois dias ao acaso por bosques cerrados em busca de Mandricardo, a fim de terminar um duelo interrompido. A busca é vã, e, nas suas deambulações, Orlando subitamente encontra-se num lugar aprazível, em que a erva tenra cresce junto a um riacho de águas cristalinas, onde há pastores e rebanhos e, sob um monte, uma gruta. Decide deter-se e repousar. Porém, passeando o olhar em volta, apercebe-se de que nas árvores há palavras, nomes e monogramas gravados.

Um olhar mais apurado revela-lhe a caligrafia de Angelica, que bem conhece. Mas logo procura explicações aleatórias para aquilo que tem diante dos olhos, e que se recusa a aceitar. Tenta por todos os modos alterar a realidade e enganar-se a si próprio:

Olhando a toda a volta, viu inscritos muitos arbustos na margem umbrosa. Quando os olhos neles deteve fitos, reconheceu da sua diva a prosa.

Era este lugar um dos já descritos, onde vinha, de Medoro amorosa, da casa do pastor ali vizinha, a bela dama, do Catai rainha. Angelica e Medoro em mil laçadas, juntos ligados, em cem lugares vê. Quantas são as letras, quantas picadas com que Amor fere seu peito sem mercê. Procura o pensamento mil jogadas para não crer em quanto, mau grado, crê: outra Angelica (para crer se encarniça) 
seu nome escreveu naquela cortiça.

Depois diz: - Mas na letra sou versado;

quantas eu tenho delas visto e lido.

Pode este Medoro ser inventado:

talvez me tenha dado este apelido.

(XXIII:102, 103, 104:1-4)

Chega por fim perto da gruta e desmonta. Era aquele o lugar onde Angelica e Medoro se abrigavam e se amavam nas horas mais quentes do dia, encontrando-se coberto de inscrições, tanto no interior quanto no exterior. Medoro, soldado sarraceno, escrevera sobre a entrada da gruta um texto, na sua língua, em louvor do lugar, pedindo a quantos ali passassem que o respeitassem e honrassem:
Em árabe estava escrito, que o conde percebia tão bem como latim; entre muitas línguas a que responde, presente tinha aquela o paladim; evitou-lhe muita vez danos, onde foi entre os Sarracenos andarim; mas não se gabe se disso houve fruto; que ora um dano tem que ao resto dá luto. Três vezes, quatro, seis leu o inscrito o infeliz, mas procurando em vão que ali não estivesse o que estava escrito;

(XXIII:110, 111:1-3)

Orlando vem depois a encontrar idênticos monogramas e inscrições nas paredes, portas e janelas da casa do pastor onde pernoita, a mesma que abrigara também os dois amantes. Se dúvidas tivera, o próprio pastor as dissipa, confirmando-lhe o idílio e as identidades dos seus protagonistas. 
Depois de uma noite insone, passada no mesmo leito que acolhera Angelica e Medoro, Orlando regressa ao lugar aprazível e dá largas à sua ira, destruindo toda a natureza:

\author{
Ver a sua injúria escrita no monte \\ tanto o irou que nele não ficou grama \\ que não fosse ódio, raiva, ira assanhada; \\ mais não esperou: desembainhou a espada. \\ Cortou inscrito, pedra, e até ao céu \\ fez subir voando cada fragmento. \\ Pobre gruta e árvores que pareceu \\ terem de Angelica e Medoro assento! \\ Ficaram de modo a sombra ou aléu \\ não mais darem a pastor ou armento; \\ e a fonte, que fora tão clara e pura, \\ contra tanta ira não foi segura;
}

(XXIII:129:5-8, 130)

Sem dormir nem comer, permanece três dias e três noites naquele espaço, estirado no solo, fixando o céu, enquanto na sua mente vai fermentando a insânia que acabará por transformá-lo num ser bestializado. Ao quarto dia ergue-se, e despoja-se dos últimos símbolos da racionalidade:

Aqui fica o elmo, além fica o escudo, longe os arneses, mais longe a couraça; as suas armas, em conclusão, tudo aqui e acolá o bosque devassa. Rasgou os panos, e mostra desnudo o ventre, o peito e as costas onde passa; começa a grande insânia, e tão horrenda que outra maior que esta se não desvenda. 
De quanto atrás se conta, deduz-se que o acto de leitura foi uma fatalidade para Orlando. Ficamos a saber que, além do francês, sua língua-mãe, ele conhece outros idiomas, entre os quais o latim e o árabe, e que o facto de conhecer outras línguas além da sua lhe foi funesto.

Observamos, no desfecho deste episódio, os efeitos que um acto de leitura pode produzir em alguém. Ler um texto que se encontra por acaso pode não ser um acto inconsequente. Conhecer outras línguas além da nossa língua-mãe, saber interpretá-las e traduzi-las, pode ser perigoso e redundar em desgraça.

Inquietante para um tradutor é o facto de a loucura de Orlando se dar em consequência de um acto de leitura e de uma capacidade para compreender e traduzir outras línguas para além da dele.

Ao destruir toda a natureza, o que Orlando procura é destruir as palavras e os textos que leu. Ele não quer que a verdade lhe seja revelada, embora a tenha perante os seus olhos. O que ele pretende é suprimir essa verdade, negar esses factos de que tomou conhecimento através da leitura e da tradução; quer acreditar apenas naquilo que lhe convém, porque aquela realidade não se integra nas suas convicções.

Lendo, aprendemos. A leitura modifica-nos, torna-nos permeáveis a outras ideias e a novas propostas. Mas nem tudo o que lemos nos agrada. Orlando destrói o ameno cenário pastoril, com a intenção de eliminar os textos nele impressos e os apagar da sua vida. Porém, será tal coisa possível? Será que ao apagar um texto se apaga a sua memória?

Há leituras que fizemos que são inapagáveis. De nada serve pretendermos apagar certas coisas. Os textos que lemos e que nos tocaram, jamais os conseguiremos suprimir da nossa memória. Eles virão sempre à tona, porque o acto de leitura gravou-os na nossa mente e, de alguma maneira, modificou-nos. São indeléveis. As leituras que fazemos ficam para sempre em nós, tal como os efeitos que 
em nós produziram e as circunstâncias da nossa vida que a elas ficaram associadas.

A incapacidade, a impotência para destruir o conhecimento cognitivo que adquiriu através da leitura, leva Orlando à loucura. Pretendendo integrar aquela realidade nas suas convicções rígidas e não o conseguindo, entra na via da insânia.

Orlando precisava de ter sido capaz de assimilar a realidade, reconfigurando as suas convicções. Temos de saber reescrever as nossas premissas e crenças, quando percebemos que estavam erradas. O mais valoroso dos paladinos de Carlos Magno, antes tido por tão sensato, não o fez, permitindo que um acto de leitura e tradução o tivesse privado do siso e o transformasse numa criatura bruta e irracional.

$\mathrm{Na}$ segunda metade da geometria do poema, os factos vão conjugar-se no sentido de Orlando recuperar o siso perdido, como que renascendo num mundo novo, em que a rigidez do código cavaleiresco se esboroou, em que ele terá olvidado Angelica.

Só a loucura pôde apagar da sua mente o registo daquele acto de leitura e permitir que, com a intervenção de agentes exteriores, as premissas que regiam a sua conduta fossem reconfiguradas.

Para chegarmos a um bom entendimento das coisas, é necessário cometermos erros. Para vermos algo com lucidez, é preciso, como sustenta Paul de Man, passar por um momento de cegueira. Só depois se dá a iluminação. 